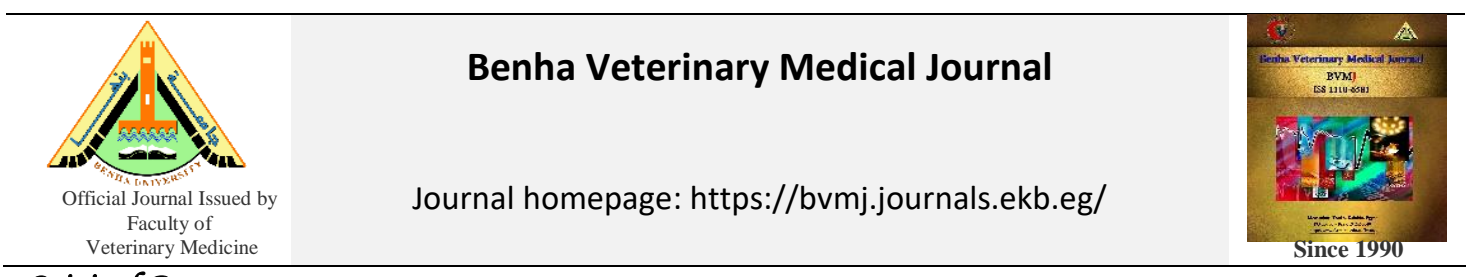

Original Paper

\title{
Biochemical study on the use of modern alternative methods for controlling bacterial enteritis in broiler chicken
}

Afaf D. Abdel-Mageid1, Yakout A. El Senosi1, Sara Hassan Abd El-Hamid*1 and Sawsan, S. El Basuni2

${ }^{I}$ Department of Biochemistry Faculty of Veterinary Medicine, Benha University

${ }^{2}$ Department of Avian and Rabbit diseases Faculty of Veterinary Medicine, Benha University

\section{ARTICLE INFO}

\begin{tabular}{l}
\hline Keywords \\
Grapefruit extract \\
salmonella \\
Herbal treatment \\
\hline Received $07 / 07 / 2021$ \\
Accepted $15 / 07 / 2021$ \\
Available On-Line \\
01/10/2021
\end{tabular}

\begin{abstract}
Total of one-hundred 1-day old broiler chicks were used for 21-days experimental period. Chicks were divided into 5-groups.G1; no treatment (control negative), G2; was inoculated with $0.1 \mathrm{ml}$ of $\left(1 \times 10^{8}\right)$ Salmonella entertidis (S. entertidis) at first day of age via crop gavage and kept as positive control., G3; was inoculated with $0.1 \mathrm{ml}$ of $\left(1 \times 10^{8}\right)$ S. entertidis at $1^{\text {st }}$ day of age via crop gavage and was treated with grapefruit peels extract $0.5 \mathrm{mg} / \mathrm{mL}$ orally in drinking water from the second day till the seventh day of age., G4; was inoculated with $0.1 \mathrm{ml}$ of $\left(1 \times 10^{8}\right)$ S.entertidis at $1^{\text {st }}$ day of age via crop gavage and was treated with Panflor ${ }^{\circledR} 1 \mathrm{ml} / \mathrm{L}$ orally in drinking water from the second day till the seventh day of age.G5; was inoculated with $0.1 \mathrm{ml}$ of $\left(1 \times 10^{8}\right) S$. entertidis at $1^{\text {st }}$ day of age via crop gavage and was treated with a combination of grapefruit peels extract $0.5 \mathrm{mg} / \mathrm{ml}$ and Panflor ${ }^{\circledR} 1 \mathrm{ml} / \mathrm{L}$ orally in drinking water from the second day till the seventh day of age. The growth performance was estimated. Serum samples were collected from each group at $10^{\text {th }}$ and 21 days of age for estimation of (ALT, AST, GGT, Urea, Creatinine and Lipase). The results showed that the treatment with grapefruit peels extract and/or antibiotic in groups 3, 4 and5 showed a substantial decrease in (ALT, AST, GGT and lipase activity) with the lower serum urea and creatinine concentrations compared to group 2 at $10^{\text {th }}$ and 21 days. It was concluded that grapefruit peels extract can be used in control S. entertidis in chicken.
\end{abstract}

\section{INTRODUCTION}

Poultry production is one of the most important sectors providing high quality protein for human consumption all over the world. Several challenges facing the poultry production as the infectious diseases, excessive antibiotic use either for therapeutic or prophylactic purposes, and the appearance of bacterial resistant strains (Azza et al., 2012). The majority of bacterial pathogens, including pathogenic salmonella species, have various virulence features that allow them to penetrate and live within the host, eventually causing disease (Bowe et al., 1998).Salmonella enteritidis $(S$. enteritidis )is among the most prevalent salmonella strains found in poultry products, and it is regarded a serious international public health and economic concern, causing a variety of syndromes in humans such as enteric fever, bacteremia, focal infection, and enterocolitis (Haiqi et al., 2013). As a result, protecting human health by eliminating food-borne pathogens from food obtained by animals has become critical for all sectors of the food supply chain (Thirabunyanon and Thongwittaya, 2012). Grapefruit is a good source of vitamins, organic acid, sugar, and phenolic compounds that has nutritional and antioxidant properties in addition to, their anticancer, antiinflammatory, antiallergenic, analgesic, antiproliferative antiviral, and antibacterial activities (Benavente-Garcia et al., 1997; Weihui et al 2020). The goal of this research was to see how grapefruit peel extract affects the control of $S$. entertidis-caused bacterial enteritis.

\section{MATERIAL AND METHODS}

\subsection{Birds and treatments}

The experiment was conducted at Benha University's Faculty of Veterinary Medicine's Laboratory Animal Research Center. A total of 100 one-day-old broiler chicks were obtained from commercial breeder farm, randomly divided into five equal groups of 20 chicks each.G1; no challenge and no treatment (control negative), G2; was inoculated with $0.1 \mathrm{ml}$ of $\left(1 \times 10^{8}\right)$ S. entertidis at 1 st day of age via crop gavage(Johny et al., 2012), and kept as positive control., G3; was inoculated with $0.1 \mathrm{ml}$ of $\left(1 \times 10^{8}\right)$ $S$. entertidis at $1^{\text {st }}$ day of age via crop gavage and was treated with grapefruit peels extract $0.5 \mathrm{mg} / \mathrm{mL}$ orally in drinking water from the second day till the seventh day of age., G4; was inoculated with $0.1 \mathrm{ml}$ of $\left(1 \times 10^{8}\right)$ S.entertidis at $1^{\text {st }}$ day of age via crop gavage and was treated with Panflor ${ }^{\circledR}$ drug $1 \mathrm{ml} / \mathrm{L}$ orally in drinking water from the second day till the seventhday of age.G5; was inoculated with $0.1 \mathrm{ml}$ of $\left(1 \times 10^{8}\right) S$. entertidis at $1^{\text {st }}$ day of age via crop gavage and was treated with a combination of grapefruit peels extract $0.5 \mathrm{mg} / \mathrm{ml}$ and Panflor ${ }^{\circledR}$ drug $1 \mathrm{ml} / \mathrm{L}$ orally in drinking water from the second day till the seventh day of age. The S. Entertidis (obtained from Laboratory of Bacteriology, Food Hygiene Department, Animal Health Research Institute, Dokki, Egypt). challenge model was performed based on previous studies of Kantachote and Charernjiratrakul, (2008). 
Grapefruit peels extract: Grapefruit peels extract was prepared by an ethanolic extraction of Citrus paradise, was used at a dose of $0.5 \mathrm{mg} / \mathrm{L}$ orally in drinking water (Abdelbaky et al., 2009) for chicks in groups 3 and 5 from the second day till the seventh day of age.

Antibiotic preparation: Panflor ${ }^{\circledR}$ was administered at a dose of $1 \mathrm{ml} / \mathrm{L}$ drinking water for chicks in groups 4 and 5 from the second day till the seventh day of age

\subsection{Growth Performance measurements}

Even during study duration (days 0-21), the broiler chicks' growth performance was assessed by recording their feed intake (FI) daily and live body weight (BW) weekly, as well as calculating their body weight gain (WG) and feed conversion ratio (FCR). Furthermore, morbidity and dead birds in each group were documented on a daily basis in order to calculate morbidity and mortality rates.

\subsection{Biochemical analysis}

After 10th and 21st days from beginning of the experiment, blood samples were taken in non-heparinized tubes via jugular vein puncture. Serum was separated and stored at 20c until use. The separated serums were used for determination ALT, AST, GGT, Urea, Creatinine, and Lipase. Serum alanine aminotransferase activity (ALT) and Serum aspartate aminotransferase (AST) activity were colorimetrically determined according to the kinetic method described by the Bergmeyeret al. (1986). Gammaglutamyl transpeptidase enzyme (GGT) was measured spectrophotometrically using the methods outlined by Szasz (1976). Serum urea concentration was quantitatively determined according to the method described by Kaplan (1984). Serum creatinine $(\mathrm{mg} / \mathrm{dl})$ concentration was measured according to method of (Bartels and Bohmer, 1971). Serum lipase was calorimetrically determined according to the method described by Kaplan1996.

\subsection{Statistical investigation}

Data obtained in this study were statistically evaluated for variance ANOVA (Significance at $\mathrm{P} \leq 0.05$ probability level) by means of SPSS/PC+ (version 16, SPSS Inc., Chicago, IL, USA) and the results were stated as the mean \pm standard error (SE). Dissimilarity between groups was investigated. Duncan's multiple Post Hoc test (Duncan, 1955).

\section{RESULTS}

\subsection{Growth performance}

Table (1) and Figure (1 and 2) provide the data of weight gain WG at 21 days post infection. Control positive group (G2) showed substantial $(\mathrm{P}<0.05)$ decrease in $\mathrm{WG}$ and substantial $(\mathrm{P}<0.05)$ increase in FCR when compared with the control negative group (G1). The treated groups (G3, G4 and G5) showed significant $(\mathrm{P}<0.05)$ increase in WG and significant $(\mathrm{P}<0.05)$ decrease in FCR when compared with the control positive group (G2). It is important to note that the herbal treatment in groups 3 and 5 showed significant $(\mathrm{P}<0.05)$ improvement in $\mathrm{WG}$ and $\mathrm{FCR}$ in comparison to the control negative and positive groups (G1 and G2). The birds in the control positive group (G2) infected orally by $S$. enteritidis in day-old without any treatments appeared with different degrees of depression, ruffled feathers, and distended abdomen, their excreta passed semisolid (soft) and loose droppings (pasty vent)

Morbidity and mortality rates of the control positive group (G2) were $40 \%$ and $10 \%$, respectively, as the highest rates in comparison to control negative group (Table 2). The herbal treated groups (G3 and G5) showed low morbidity rate as $10 \%$ when compared with the control positive group (G2). No mortalities were reported in the antibiotic treated groups (G4 and G5) as shown in the control negative group (G1).

Table (1): Effect of the grape peel extract and/or Panflor ${ }^{\circledR}$ in the treatment of the Salmonella entertidis infected broiler chicken on the weight gain and feed conversion ratio at 21 days post infection. G1: Control negative, G2 Control positive, G3: Grapefruit peels extract treatment, G4: Panflor treatment, G5: Combined Grapefruit peels extract and Panflor treatment. weight gain and feed conversion ratio measured at 21days post infection

\begin{tabular}{lrr}
\hline Group & Weight gain & Feed conversion ratio \\
\hline G1 & $624.17 \pm 10.10^{\mathrm{b}}$ & $2.03 \pm 0.02^{\mathrm{c}}$ \\
G2 & $473.17 \pm 6.52^{\mathrm{c}}$ & $2.64 \pm 0.03^{\mathrm{a}}$ \\
G3 & $714.50 \pm 26.78^{\mathrm{a}}$ & $1.78 \pm 0.07^{\mathrm{d}}$ \\
G4 & $598.17 \pm 7.97^{\mathrm{b}}$ & $2.17 \pm 0.03^{\mathrm{b}}$ \\
G5 & $728.17 \pm 9.45^{\mathrm{a}}$ & $1.71 \pm 0.02^{\mathrm{d}}$ \\
\hline The data is shown as (Mean S.E.). S.E. stands for standard error.In the same
\end{tabular}

is shown as (Mean S.E.). S.E. stands for standard error.In the same different at $(\mathrm{P}<0.05)$

Table (2): Effect of the grape peel extract and/or Panflor $\circledast$ in the treatment of the Salmonella entertidis infected broiler chicken on the morbidity and mortality rates. G1: Control negative, G2: Control positive, G3: Grapefruit peels extract treatment, G4: Panflor treatment, G5: combined Combined Grapefruit peels extract and Panflor treatment

\begin{tabular}{lcc}
\hline Group & Morbidity\% & Mortality $\%$ \\
\hline G1 & 0 & 0 \\
G2 & 40 & 10 \\
G3 & 10 & 5 \\
G4 & 20 & 0 \\
G5 & 10 & 0 \\
\hline
\end{tabular}

Table (3): Effect of the grape peel extract and/orPanflor ${ }^{\circledR}$ on the serum ALT Activity (U/L). G1: Control negative, G2: Control positive, G3: Grapefruit peels extract, G4: Panflor, G5: Mixture between Grapefruit peels extract and Panflor

\begin{tabular}{lcc} 
Panflor & \multicolumn{2}{c}{ Duration of experiment } \\
\cline { 2 - 3 } Group & 10 Days & 21 Days \\
\hline G1 & $11.80 \pm 0.58^{\mathrm{d}}$ & $18.40 \pm 1.03^{\mathrm{c}}$ \\
G2 & $55.80 \pm 3.89^{\mathrm{a}}$ & $74.80 \pm 1.07^{\mathrm{a}}$ \\
G3 & $35.20 \pm 1.66^{\mathrm{b}}$ & $33.00 \pm 1.58^{\mathrm{b}}$ \\
G4 & $35.80 \pm 1.24^{\mathrm{b}}$ & $31.00 \pm 1.52^{\mathrm{b}}$ \\
G5 & $24.40 \pm 1.36^{\mathrm{c}}$ & $19.40 \pm 1.21^{\mathrm{c}}$ \\
\hline
\end{tabular}

The data is shown as (Mean S.E.). S.E. stands for standard error.In the same column, mean values with various superscript letters are substantially different at $(\mathrm{P}<0.05)$

Table (4): Effect of the grape peel extract and/or Panflor ${ }^{\circledR}$ on Serum AST Activity (U/L). G1: Control negative, G2: Control positive, G3: Grapefruit peels extract, G4: Panflor, G5: Mixture between Grapefruit peels extract and Panflor

\begin{tabular}{lcc}
\hline \multirow{2}{*}{ Group } & \multicolumn{2}{c}{ Duration of experiment } \\
\cline { 2 - 3 } & 10 Days & 21 Days \\
\hline G1 & $22.10 \pm 1.82^{\mathrm{d}}$ & $17.80 \pm 0.86^{\mathrm{d}}$ \\
G2 & $57.56 \pm 0.70^{\mathrm{a}}$ & $55.20 \pm 1.16^{\mathrm{a}}$ \\
G3 & $40.66 \pm 1.92^{\mathrm{b}}$ & $36.40 \pm 1.47^{\mathrm{b}}$ \\
G4 & $36.14 \pm 2.33^{\mathrm{b}}$ & $36.60 \pm 1.50^{\mathrm{b}}$ \\
G5 & $29.00 \pm 0.71^{\mathrm{c}}$ & $29.00 \pm 2.93^{\mathrm{c}}$ \\
\hline
\end{tabular}

The data is shown as (Mean S.E.). S.E. stands for standard error. In the same column, mean values with various superscript letters are substantially different at $(\mathrm{P}<0.05)$

\subsection{Biochemical parameters}

Effect of the grape peel extract and/or Panflor ${ }^{\circledR}$ on serum ALT, AST, GGT activities were represented in Table (3-5). The $S$. entertidis infected bird in the control positive group G2 showed a substantial increase in ALT, AST, GGT activity compared to control negative group G1 at 10 and 21days post infection. Moreover, the treatment of the infected bird with herbal extracts and/or antibiotic in groups $3,4 \& 5$ showed a substantial decrease in ALT, AST, GGT activity compared with control positive group G2 after 10- and 21-days post infection. 
Effect of the grape peel extract and/or florfenicol on serum urea and creatinine concentrations were represented in Table (6-7). TheS.entertidisinfected bird in the control positive group G2 had significantly higher serum urea and creatinine values than the control negative group G1 at 10 and 21 days' post infection. Moreover, the treatment of the infected bird with herbal extracts and/or antibiotic in groups $3,4 \& 5$ showed a significant decrease in serum urea and creatinine concentrations compared to control positive group G2 after 10- and 21-days post infection.

Effect of the grape peel extract and/or florfenicol on the serum lipase activity was represented in Table (8). The $S$. entertidis infected bird in the control positive group G2 showed a significant increase in serum lipase activity as $847.30 \pm 52.88$ and $1270.50 \pm 42.32$ compared to control negative group G1 at 10- and 21-days post infection, respectively. Moreover, the treatment of the infected bird with herbal extracts and/or antibiotic in groups $3,4 \& 5$ showed a significant decrease in serum lipase activity compared to control positive group G2 after 10- and 21days post infection.

Table (5): Effect of the grape peel extract and/or Panflor® on serum GGT Activity (U/L). (G1: Control negative, G2: Control positive, G3: Grapefruit peels extract, G4: Panflor, G5: Mixture between Grapefruit peels extract and Panflor)

\begin{tabular}{lcc}
\hline \multirow{2}{*}{ Group } & \multicolumn{2}{c}{ Duration of experiment } \\
\cline { 2 - 3 } & 10 Days & 21 Days \\
\hline G1 & $79.76 \pm 3.30^{\mathrm{d}}$ & $91.94 \pm 4.47^{\mathrm{c}}$ \\
G2 & $114.68 \pm 1.43^{\mathrm{a}}$ & $140.80 \pm 5.29^{\mathrm{a}}$ \\
G3 & $100.48 \pm 0.98^{\mathrm{bc}}$ & $113.68 \pm 1.31^{\mathrm{b}}$ \\
G4 & $105.90 \pm 0.61^{\mathrm{b}}$ & $109.86 \pm 2.78^{\mathrm{b}}$ \\
G5 & $93.92 \pm 3.62^{\mathrm{c}}$ & $98.60 \pm 0.83^{\mathrm{c}}$ \\
\hline The data is shown as (Mean S.E.). S.E. stands for standard error. In the same column,
\end{tabular}

mean values with various superscript letters are substantially different at $(\mathrm{P}<0.05)$

Table (6): Effect of the grape peel extract and/or Panflor® on Serum Urea concentration $(\mathrm{mg} / \mathrm{dl})$. (G1: Control negative, G2: Control positive, G3: Grapefruit peels extract, G4 Panflor, G5: Mixture between Grapefruit peels extract and Panflor)

\begin{tabular}{lcc}
\hline \multirow{2}{*}{ Group } & \multicolumn{2}{c}{ Duration of experiment } \\
\cline { 2 - 3 } & 10 Days & 21 Days \\
\hline G1 & $39.70 \pm 3.05^{\mathrm{c}}$ & $37.54 \pm 4.16^{\mathrm{e}}$ \\
G2 & $80.50 \pm 2.84^{\mathrm{a}}$ & $99.14 \pm 1.21^{\mathrm{a}}$ \\
G3 & $57.20 \pm 1.55^{\mathrm{b}}$ & $61.18 \pm 3.30^{\mathrm{c}}$ \\
G4 & $55.84 \pm 2.14^{\mathrm{b}}$ & $70.72 \pm 3.89^{\mathrm{b}}$ \\
G5 & $43.36 \pm 1.16^{\mathrm{c}}$ & $48.62 \pm 1.14^{\mathrm{d}}$ \\
\hline The data is shown as (Mean S.E.). S.E. stands for standard error. In the same column, \\
mean values with various superscript letters are substantially different at $(\mathrm{P}<0.05)$
\end{tabular}

Table (7): Effect of the grape peel extract and/or Panflor® on Serum creatinine concentration (mg/dl). (G1: Control negative, G2: Control positive, G3: Grapefruit peels extract, G4: Panflor, G5: Mixture between Grapefruit peels extract and Panflor)

\begin{tabular}{lcc}
\hline \multirow{2}{*}{ Group } & \multicolumn{2}{c}{ Duration of experiment } \\
\cline { 2 - 3 } & 10 Days & 21 Days \\
\hline G1 & $0.24 \pm 0.06^{\mathrm{c}}$ & $0.24 \pm 0.01^{\mathrm{d}}$ \\
G2 & $1.77 \pm 0.10^{\mathrm{a}}$ & $2.36 \pm 0.09^{\mathrm{a}}$ \\
G3 & $0.77 \pm 0.03^{\mathrm{b}}$ & $0.92 \pm 0.03^{\mathrm{b}}$ \\
G4 & $0.70 \pm 0.04^{\mathrm{b}}$ & $1.00 \pm 0.02^{\mathrm{b}}$ \\
G5 & $0.41 \pm 0.05^{\mathrm{c}}$ & $0.65 \pm 0.06^{\mathrm{c}}$ \\
\hline \multicolumn{2}{l}{ The data is shown as (Mean S.E.). S.E. stands for standard error. In the same column, }
\end{tabular}
mean values with various superscript letters are substantially different at $(\mathrm{P}<0.05)$

Table (8): Effect of the grape peel extract and/or Panflor® on Serum Lipase Activity (U/L). (G1: Control negative, G2: Control positive, G3: Grapefruit peels extract, G4: Panflor, G5: Mixture between Grapefruit peels extract and Panflor)

\begin{tabular}{lcc}
\hline \multirow{2}{*}{ Group } & \multicolumn{2}{c}{ Duration of experiment } \\
\cline { 2 - 3 } & 10 Days & 21 Days \\
\hline G1 & $483.68 \pm 31.68^{\mathrm{c}}$ & $538.94 \pm 19.45^{\mathrm{c}}$ \\
G2 & $847.30 \pm 52.88^{\mathrm{a}}$ & $1270.50 \pm 42.32^{\mathrm{a}}$ \\
G3 & $588.32 \pm 14.90^{\mathrm{b}}$ & $760.32 \pm 9.90^{\mathrm{b}}$ \\
G4 & $620.34 \pm 3.62^{\mathrm{b}}$ & $778.64 \pm 12.02^{\mathrm{b}}$ \\
G5 & $548.42 \pm 20.54^{\mathrm{bc}}$ & $726.90 \pm 8.55^{\mathrm{b}}$ \\
\hline \multicolumn{2}{l}{ The data is shown as (Mean S.E.). S.E. stands for standard error. In the same column, } \\
mean values with various superscript letters are substantially different at $(\mathrm{P}<0.05)$
\end{tabular}

\section{DISCUSSION}

Restrictions of antibiotics used in poultry have pushed research toward finding appropriate alternatives such as direct-fed microbial, enzymes, organic acids, plant oils, herbal extracts, etc. to overcome the growing challenges for the poultry industry to cope with enteric pathogens as nontyphoidal Salmonella sps., Clostridium perfringens, Campylobacter sps., and Escherichia coli (Adhikari et al 2019). Grapefruit (Citrus paradisi. L) belongs to the Citrus genus, a category of flowering plants in the family Rutaceae (Gupta et al., 2011). Grapefruit Peel is considered as a cheap by-product of the fruit which is a rich source of nutrients including vitamin $C$, essential oils such as terpens and aliphatic sesquiterpene and dietary fiber that showed invitro a wide spectrum of antimicrobial activities against Staphylococcus aureus, Staphylococcus epidermidis, Escherichia coli, Salmonella typhimurium, and Etc., with 11 to $53 \mathrm{~mm}$ inhibition zone (Uysal et al. 2011).

In the present study, the effects of the grapefruit peel extract and/or florfenicol in the treatment of the $S$. enteritidis infected broiler chicken in vivo trials were evaluated.

The grapefruit peel extract and/or florfenicol showed some level of protection against the negative impacts of the $S$. entertidis pathogen on the growth performance and clinical findings (Tables $1-2)$ through substantial $(\mathrm{P}<0.05)$ increase in WG and substantial $(\mathrm{P}<0.05)$ decrease in FCR, morbidity, and mortality rates due to their antibacterial properties against $S$. enteritidis which necessitated the better performance. This agreed with Oluremi et al. (2006) and Ebrahimi et al., 2014 who reported that orange or grapefruit waste have positively impacted the growth performance in broiler production with their feed supplementation. Citrus peel extraction was recently discovered to raise the systemic total protein level in the blood of chicken, which could be due to improved nutritional absorption in the intestinal epithelium(Akbarian et al. 2013).

On the other hand, the birds in the control positive group (G2) infected orally by S. enteritidis in one-day-old without any treatments appeared with different degrees of depression, ruffled feathers, and distended abdomen, their excreta passed semisolid (soft) and loose droppings (pasty vent). Furthermore, a substantial $(\mathrm{P}<0.05)$ decrease in WG and substantial $(\mathrm{P}<0.05)$ increase in FCR, morbidity, and mortality rates were reported when compared with the control negative group (G1). This result came compatible with the findings of Belihet al., (2016) and Okuneye et al., (2016) that recorded the lowest WG values and highest values of FCR, morbidity, and mortality rates for control positive, followed by antibiotic, aroma-biotic and probiotic treated groups. The salmonella infections are owing to damage of the intestinal tract which results in low feed conversion efficiency and a lower rate of body weight gain, extend to be an overt disease with high mortality (Porter 1998).

As appeared in Tables (3-8), the $S$. entertidis infected birds in the control positive group G2 showed a substantial increase in ALT, AST, GGT and lipase activities with the highest serum urea and creatinine concentrations when compared to control negative group G1 at 10- and 21-days post infection.After salmonella infection, $S$. entertidis could colonise the intestine and cause a chronic infection of the liver, which is the major organ for lipid metabolism in chicken, with lower pyruvate levels and down-regulation of lipid metabolism genes. (Coble et al., 2012). 
The treatment of the infected bird with herbal extracts and/or antibiotic in groups 3, 4and 5 showed a substantial decrease in ALT, AST, GGT and lipase activities with the lower serum urea and creatinine concentrations when compared to control positive group G2 after 10- and 21days post infection. This result partially agreed with Akbarian et al. 2013) who found the orange peel extract, lemon peel extract and their combination being able to positively modify blood antioxidant enzyme activities, biochemical parameters like total protein, serum lactate dehydrogenase, AST and ALT activities in regard to ameliorate the heat stress. Grapefruit peel extract can limit the growth of pathogenic bacteria while supporting the growth of normal resident microflora (Pourhossein et al. 2012) and increase nutritional absorption in the intestinal epithelium, in addition to providing several vitamins with anti-oxidant properties. (Akbarian et al. 2013). All these factors led to ameliorate the negative effects of $S$. entertidis infection in newly hatched broiler chicks on growth performance, and biochemical changes via use of the grapefruit peel extract alone or in combination with antibiotic.

\section{CONCLUSION}

From the obtained results it could be concluded that Grapefruit peels extract has the availability to use as a safe, economic, efficient and natural alternative to antibiotic in the therapy of the bacterial enteritis in broiler chickens.

\section{CONFLICT OF INTEREST}

The authors declare that they have no conflicts of interest for current data

\section{REFERENCES}

1. Abdelbaky, M.S., H.F. El Mehiry and N.K.M. Ali, 2009. effect of citrus peel on hypercholesterolemic rats. Proceeding of the 1 st international and $4^{\text {th }}$ Arab annual scientific conference on Academic Accreditation for higher education Institutions and programs in Egypt and Arab world reality and expectations, April 8 - 9, 2009, Mansoura University, Egypt, PP: $1627-1639$.

2. Abozaid, O. A. R., Aziza, S. A. H., Moawed, F. S. M., and Kasseb, S. G. (2018). Avocado Oil Attenuates Diethylnitrosamine Induced-Hepatic Carcinogenesis. Benha Veterinary Medical Journal, 35(2), 344-353.

3. Adhikari B, Hernandez-Patlan D, Solis-Cruz B, Kwon YM, Arreguin MA, Latorre JD, Hernandez-Velasco X, Hargis BM and Tellez-Isaias G (2019): Evaluation of the Antimicrobial and Anti-inflammatory Properties of Bacillus-DFM (Norum ${ }^{\mathrm{TM}}$ ) in Broiler Chickens Infected with Salmonella Enteritidis. Front. $\quad$ Vet. Sci. 6:282. doi: 10.3389/fvets.2019.00282

4. Ahmad, M., Ansari, M. N., Alam, A., and Khan, T. H. (2013). Oral dose of citrus peel extracts promotes wound repair in diabetic rats. Pakistan journal of biological sciences: PJBS, 16(20), 1086-1094.

5. Akbarian A., Golian A., Gilani A., Kermanshahi H., Zhaleh S. , Akhavan A., De Smet S and Michiels J. 2013. Effect of feeding citrus peel extracts on growth performance, serum components, and intestinal morphology of broilers exposed to high ambient temperature during the finisher phase. Livest Sci. 157:490-497.

6. Azza, H.A., Kamel, H.H., Walaa, M.A., Olfat, S.H.M., Amira, H.M., 2012. Effect of bactocell ${ }^{\circledR}$ and revitilyte-plustm as probiotic food supplements on the growth performance, hematological, biochemical parameters and humoral immune response of broiler chickens. World Applied Sciences Journal $18,305-316$
7. Bartels, H., and Böhner, M. Clin. Chim. Acta. 32: 81 (1971).

8. Belih, S., EL-Hadad, S., Amen, G., and Basiony, M. R. (2016). Influence of sodium butyrate on salmonella infection in broiler chicks. Benha Veterinary Medical Journal, 31(2), 21-32.

9. Benavente-García, O., Castillo, J., Marin, F. R., Ortuño, A., \& and Del Río, J. A. (1997). Uses and properties of citrus flavonoids. Journal of agricultural andfood chemistry, 45(12), 4505-4515.

10. Bergmeyer HU, Hørder M and Rej R (1986): International Federation of Clinical Chemistry (IFCC) Scientific Committee, Analytical Section: approved recommendation (1985) on IFCC methods for the measurement of catalytic concentration of enzymes. Part 3. IFCC method for alanine aminotransferase (L-alanine: 2-oxoglutarate aminotransferase, EC 2.6.1.2). J Clin Chem Clin Biochem. Jul 1986; 24(7):481495.

11. Coble, D.J., Sandford, E.E., Ji, T., Abernathy, J., Fleming, D., Zhou, H. and Lamont, S.J. (2012). Impacts of Salmonella Enteritidis infection on liver transcriptome in broilers. Genesis, 51, 357-364. doi: 10.1002/dvg.22351

12. Duncan, D. B. (1955): New multiple range and multiple F test. Biometrics, 11:1- 42.

13. Ebrahimi, A.; Qotbi, A. A. A.; Seidavi, A. and Bahar, B. (2014) The effects of dietary supplementation of Citrus sinensis peel extract on production and quality parameters of broiler chicken, Journal of Applied Animal Research, 42:4, 445-50, DOI: 10.1080/09712119.2013.875916

14. Gupta, V., Kohli, K., Ghaiye, P., Bansal, P., and Lather, A. (2011). Pharmacological potentials of Citrus paradisi-an overview. Int J Phytother Res, 1(1), 8-17.

15. Haiqi, H., Kenneth, J.G., Christina, L.S., David, J.N., Michael, H.K., 2013. Nitric oxide as a biomarker of intracellular salmonella viability and identification of the bacteriostatic activity of protein kinase inhibitor H-89. PLoS One 8, e58873.

16. Johny, A.K., Mattson, T., Baskaran, S.A.,Amalaradjou, M.A., Babapoor, S., March,B., Valipe, S., Darre, M., Hoagland, T.,Schreiber, D., Khan, M.I., Donoghue, A.,Donoghue, D., Venkitanarayanana, K.,2012. Reduction of Salmonella entericaSerovar Enteritidis Colonization in 20-Day-Old Broiler Chickens by the Plant-DerivedCompounds transCinnamaldehyde andEugenol. Appl Environ Microbio 78 2981-2987.

17. Kantachote, D., Charernjiratrakul, W., 2008.Selection of lactic acid bacteria fromfermented plant beverages to use asinoculants for improving the quality of thefinished product Pakistan J. Biol. Sci. 11, 1-8.

18. Kaplan A., et al. (1984):Tryglycerides. Clin Chem The C.V. Mosby Co. St Louis. Toronto. Princeton; 437 and Lipids 1194-1206 Kaplan, L.A., Pesce, A.J.: "Clinical Chemistry", Mosby Ed. (1996)

19. Okuneye OJ, Ogunfolabo LA, Fasanmi OG. 2016; Performance and physiological responses of Salmonella Enteritidis challenged broilers fed diets containing antibiotic, probiotic and aromabiotic. J Dairy Vet Anim Res. 3(3):106110. DOI: $\underline{10.15406 / \text { jdvar.2016.03.00081 }}$

20. Oluremi OIA, Ojighen VO, Ejembi EH. 2006. The nutritive potentials of sweet orange (Citrus sinensis) rind in broiler production. Int J Poult Sci. 5(7):613-617.

21. Porter RE.1998 Bacterial enteritides of poultry. Poult Sci.;77(8):1159-1165

22. Pourhossein, Z., A. A. A. Qotbi, and A. Seidavi. 2012. "Investigation on the Effects of Different Levels of Citrus Sinensis Peel Extract on Gastrointestinal Microbial Population in Commercial Broilers." African Journal of Microbiology Research 6: 6370-6378. doi:10.5897/AJMR12.828

23. Szasz, G. 1976. Reactionrate method for gamma glutamyl transferase activity in serum. Clinical chemistry, 22: $2051-$ 55.

24. Thirabunyanon, M., Thongwittaya, N., 2012. Protection activity of a novel probiotic strain of Bacillus subtilis against Salmonella Enteritidis infection. Res Vet Sci 93, 74-81.

25. Uysal, B., Sozmen, F., Aktas, O., Oksal, B. S., and Kose, E. O. (2011). Essential oil composition and antibacterial activity of the grapefruit (Citrus Paradisi. L) peel essential oils obtained by solvent-free microwave extraction: comparison 
with hydrodistillation. International journal of food science \& technology, 46(7), 1455-1461.

26. Weihui Deng, Ke Liu, Shan Cao, Jingyu Sun, Balian Zhong, Jiong Chun, Chemical composition, Antimicrobial,
Antioxidant, and Anti-proliferative properties of Grapefruit essential oil prepared by Molecular distillation, Molecules, 10.3390/moecules 25010217, 25, 1, (217), (2020). 